\title{
Receptor Overall Status
}

National Cancer Institute

\section{Source}

National Cancer Institute. Receptor Overall Status. NCI Thesaurus. Code C125989.

A qualitative assessment of the status of a biological specimen with regards to a cellular receptor. 